\title{
Espécies lenhosas nativas com potencial de uso em sistema silvipastoril em Mato Grosso do Sul
}

\author{
Paulo Ricardo Lima ${ }^{1}$ \\ Ubirajara Contro Malavasi² \\ Martios $\mathrm{Ecco}^{3}$ \\ Jean Sérgio Rosset ${ }^{4}$
}

\section{Resumo}

Sistemas Silvipastoris (SSP) são associações naturais, planejadas ou convertidas de pastagens com espécies arbóreas. Quando manejado corretamente, este sistema conserva o solo e os recursos hídricos e promove o sequestro de carbono e o aumento da biodiversidade. Com o propósito de obter informações quantitativas sobre o assunto, realizou-se um estudo sobre os benefícios e a importância da escolha das diversas espécies no SSP, relatando algumas espécies lenhosas nativas com potencial de uso em sistemas silvipastoris no Estado de Mato Grosso do Sul. O trabalho foi realizado através de revisão literária, com contexto objetivo e coeso. Com este estudo é possível dizer que o sucesso do SSP depende da escolha e da adaptação das espécies arbóreas às condições locais de implantação. Contudo, no Estado de Mato Grosso do Sul, algumas espécies nativas se adaptam bem ao SSP e podem ser utilizadas, como a aroeira ( $M$. urundeuva), o bocaiúva ( $A$. aculeata), o chico-magro (G. ulmifolia) e o cumbaru (D. alata).

Palavras-chave: Árvores. Associação. Pastagem. Silvicultura.

\section{Introdução}

A pecuária de corte e leiteira é uma atividade de importância econômica no Estado de Mato Grosso do Sul. Porém, os sistemas convencionais de criação de gado possuem baixos parâmetros produtivos, são suscetíveis e vulneráveis às mudanças climáticas das estações, costumam gerar lucros baixos e não garantem a sustentabilidade dos ecossistemas no tempo (MURGUEITIO et al., 2012).

Com frequência, o sistema convencional de criação de gado é associado com a degradação ambiental, haja vista que grande parte das atuais áreas de pastagem estiveram ocupadas com flo-

\footnotetext{
1 Mestrando do Programa de pós-graduação em agronomia, área de concentração em Produção Vegetal. E-mail: paulorikardoo@ hotmail.com. (67) 3475-1186. Centro de Ciências Agrárias, Rua Pernambuco, 1777 - Caixa Postal: 91, CEP: 85960-000 - Marechal Cândido Rondon - PR.

2 Universidade Estadual do Oeste do Paraná - UNIOESTE, Professor Associado - Centro de Ciências Agrárias (CCA) - Programa de pós-graduação em agronomia, área de concentração em Produção Vegetal. E-mail: biramalavasi@yahoo.com.br. Centro de Ciências Agrárias, Rua Pernambuco, 1777 - Caixa Postal: 91, CEP: 85960-000 - Marechal Cândido Rondon - PR.

3 Universidade Estadual do Oeste do Paraná - UNIOESTE. Doutorando em agronomia, área de concentração em Produção Vegetal. E-mail: eccoagronomia@hotmail.com. Centro de Ciências Agrárias, Rua Pernambuco, 1777 - Caixa Postal: 91, CEP: $85960-000$ Marechal Cândido Rondon - PR.

4 Universidade Estadual do Oeste do Paraná - UNIOESTE. Doutorando em agronomia, área de concentração em Produção Vegetal. jsrosset@hotmail.com. Centro de Ciências Agrárias, Rua Pernambuco, 1777 - Caixa Postal: 91, CEP: 85960-000 - Marechal Cândido Rondon - PR.
} 
restas e agricultura (SEGHESE, 2006). Todavia, essas áreas encontram-se atualmente em estado de degradação que, além de contribuir para reduzir a produção e a rentabilidade das propriedades agropecuárias, também causam danos ao meio ambiente (MONTOYA; BAGGIO, 2000).

Desse modo, é necessário repensar a forma de produzir alimentos. Nesse aspecto, a busca por sistemas alternativos aponta os Sistemas Agroflorestais (SAFs), sistemas produtivos que incluem árvores em consórcio ou associação com culturas agrícolas ou criação animal e que são uma alternativa eficiente (DUBOIS, 1992; DANTAS, 1994; MACEDO; CAMARGO, 1994; RIBASKI et al., 2005).

Segundo Nepomuceno e Silva (2009), Sistemas Silvipastoris, uma modalidade dos SAFs, são associações naturais, planejadas ou convertidas de pastagens com espécies arbóreas, com potencial para aumentar a eficiência de uso da terra e dos demais recursos naturais, resultando em maior diversidade produtiva na propriedade rural.

O Sistema Silvipastoril (SSP) é constituído por pastagem adequadamente arborizada que consiste na combinação intencional de árvores, pastagens e gado na mesma área e ao mesmo tempo, manejados de forma integrada, com o objetivo de incrementar a produção por unidade de área (DULEBA, 2009).

O SSP apresenta grande potencial de benefícios econômicos e ambientais tanto para os produtores como para a sociedade. Os SSP são sistemas multifuncionais nos quais existe a possibilidade de intensificar a produção pelo manejo integrado dos recursos naturais, evitando sua degradação (PORFÍRIO DA SILVA, 2006). Essa atividade, além de melhorar a produtividade através do manejo integrado dos recursos naturais, reduz os processos erosivos, melhora a conservação de corpos d'água, aumenta a captura e a fixação do carbono, proporciona maior bem estar aos animais, aumenta a biodiversidade e reduz a pressão sobre as vegetações naturais remanescentes (FRANKE; FURTADO, 2001; ANDRADE et al., 2002; CARVALHO et al., 2002).

No Brasil, a adoção do SSP ainda depende de muito trabalho de divulgação das vantagens do sistema, bem como de estudos sobre a adaptação de espécies arbóreas a diferentes condições climáticas e de solo, visando identificar espécies alternativas às exóticas mais frequentemente utilizadas, como a Grevillea spp. e Eucalyptus spp. (BAGGIO; CARPANEZZI, 1998; CARVALHO et al., 2002).

O Centro-Oeste brasileiro apresenta grande potencial de aplicação dos SAFs, em especial de SSP (MELOTTO et al., 2009). Existem grandes áreas de pastagens degradadas de criação extensiva, bacias leiteiras com problemas de cobertura vegetal viva durante o inverno, entre outras potencialmente aproveitáveis (DANIEL et al., 2000).

No Estado de Mato Grosso do Sul, dos quase 36 milhões de hectares, 63\% são utilizados com pastagens e $16 \%$ estão com florestas e outros tipos de vegetações naturais. Diante da importância sócio-econômica das cadeias produtivas da carne e do leite para a sociedade sul-mato-grossense e das divisas que proporcionam, o desafio é o seu desenvolvimento em bases sustentáveis e com justiça social (SILVA, 2003).

As áreas de pastagem do Mato Grosso do Sul estão sob uma condição climática que determina estresse térmico calórico em graus mediano e severo para os animais sem proteção no período de outubro até março. Outro agravante está na estação seca, durante a qual se observa baixo rendimento forrageiro e comprometimento no valor nutricional da forragem. Na metade sul do Estado, a ocorrência de geadas (embora de intensidade e frequência baixas) é um agravante para a produção das forrageiras. Ambos os aspectos constituem um importante problema para a pecuária na região, tendo reflexos no desempenho animal (SILVA, 2003).

Dados do Instituto Brasileiro de Geografia e Estatística (INSTITUTO BRASILEIRO DE GEOGRAFIA E ESTATÍSTICA, 2006) indicam que 782.577 hectares de pastagem plantadas dos estabelecimentos agropecuários do Estado do Mato Grosso do Sul estão degradadas ou em processo de degradação devido ao mau manejo adotado nessas áreas, o que pode ser um indício de que, entre outras causas, os atuais sistemas de uso das terras podem não estar conseguindo assegurar a capacidade produtiva dos recursos existentes. 
Portanto, este estudo não pretende esgotar o assunto, e sim apenas focar os benefícios do SSP e a importância da escolha das diversas espécies lenhosas, relatando algumas espécies nativas com potencial de uso em SSP no Estado do Mato Grosso do Sul.

\section{Revisão de literatura}

\subsection{Vantagens do SSP}

O SSP traz diversos benefícios para o meio ambiente, quando comparado à pastagem tradicional, a qual não possui integração planejada de árvores ou arbustos no sistema pecuário. Dentre os benefícios, podemos citar a conservação do solo, a conservação dos recursos hídricos, a promoção do sequestro de carbono e o aumento na biodiversidade (LEME et al., 2005; DIAS FILHO, 2006).

Segundo Melado (2002), a existência de árvores em pastagens confere inúmeras vantagens aos animais, às forrageiras e ao solo, pois os animais encontram nas árvores a proteção contra o excesso de insolação, chuva e vento, proporcionando um conforto que irá finalmente refletir numa melhoria da produção do animal. As plantas forrageiras, principalmente nas regiões tropicais, têm seu desenvolvimento prejudicado pelo excesso de insolação nas horas mais quentes do dia, mas as forrageiras que crescem à sombra das árvores permanecem viçosas enquanto as que se encontram em pleno sol murcham.

Ainda segundo Melado (2002), o solo é muito favorecido pelas árvores, que atuam retirando nutrientes de camadas mais profundas do solo e os depositando na superfície através das folhas e gaIhos que caem (ciclagem de nutrientes), protegendo com sua sombra a micro e a meso vida do solo, que, por sua vez, usam os restos vegetais e os dejetos do gado como alimento, contribuindo para a disponibilização de nutrientes antes indisponíveis às plantas, o que tende a melhorar a fertilidade do solo e, consequentemente, a área produtiva.

Dentre os inúmeros benefícios, pode-se dizer que o SSP é um investimento de longo prazo. As árvores integradas a esse sistema podem ser utilizadas no manejo do risco econômico, no planejamento da aposentadoria e como forma de transferir riqueza entre gerações (ABEL et al., 1997).

Diversos trabalhos evidenciaram a lucratividade do SSP, como, por exemplo, Marlats et al. (1995), que comparam os resultados obtidos entre a monocultura de floresta, monocultura de pastagem e SSP com 250 e 416 árvores por hectare, apresentando o SSP as melhores taxas internas do retorno investido, superando a renda líquida obtida nas monoculturas. Outro exemplo da lucratividade do SSP encontra-se no trabalho de Ribaski et al. (2003), que avaliaram um SSP com 185 árvores de Corymbia citriodora por hectare aos 11 anos de idade. Esse SSP apresentou, além da produção de forrageira, um estoque de $204 \mathrm{~m}^{3}$ de madeira por hectare.

\subsection{Desvantagens do SSP}

Apesar dos benefícios imputados ao SSP, é importante ressaltar que esse sistema não se constitui em uma solução para os diversos problemas inerentes às pastagens tropicais, como por exemplo, a presença de árvores e arbustos principalmente sem manejo, devido ao sombreamento e, em alguns casos, pela competição por água e pastagem. Um exemplo ocorre em algumas espécies arbóreo-arbustivas que apresentam abundante queda de folhas, cuja decomposição é lenta, podendo o acúmulo dessa serrapilheira prejudicar o rebrote ou a germinação e o crescimento da pastagem (DIAS FILHO, 2006).

Segundo Montoya e Baggio (2000), pode-se dizer que há desvantagens no SSP, quando:

a) os custos associados à implantação e manutenção das árvores forem elevados; 
b) a competição por luz, água e nutrientes não for devidamente manejado;

c) existir um número reduzido de árvores, o que promove a competição do gado debaixo das mesmas, provocando a redução da área de pastagem e a compactação do solo.

As diversas desvantagens podem ser minimizadas, como, por exemplo, o sombreamento excessivo, que pode reduzir a produção das gramíneas. Alternativas para manter a produtividade neste caso incluem podas e raleamento (desbaste) das árvores, que podem inclusive gerar renda direta (venda de escoras, postes) ou indireta através do uso na propriedade rural. Outra forma mais eficiente de minimizar os problemas do SSP está nas escolhas das espécies, visto que planejamento e manejo adequado são essenciais em qualquer atividade que busca a sustentabilidade (NICODEMO, 2005).

\subsection{Importância da escolha de espécies}

No estabelecimento de SSP ou de pastagens arborizadas, três situações relacionadas com o plantio dos componentes do sistema podem ocorrer:

a) as árvores são introduzidas em pastagem já existentes;

b) árvores e gramíneas são plantadas simultaneamente;

c) as gramíneas são introduzidas em áreas de plantios florestais ou maciços arbóreos naturais (CARVALHO et al., 1995).

O primeiro grande desafio para o estabelecimento com sucesso destas plantações é a definição das espécies a serem utilizadas. Existem poucas informações silviculturais a respeito de árvores nativas. As espécies já conhecidas, embora aptas para atender à produção industrial, geralmente não são as mais adequadas para objetivos como a produção de pequena escala e a proteção ambiental (KAGEYAMA; CASTRO, 1989).

As necessidades e as justificativas para o reflorestamento com árvores de uso múltiplo em monocultivo ou em SAFs são muitas e variam de acordo com as características ambientais e sócio-econômicas de cada região, sendo que um dos aspectos mais importantes é a identificação de espécies lenhosas adequadas para serem usadas como componentes desses sistemas (FRANKIE et al., 2000).

A escolha do componente arbóreo-arbustivo de um SSP deve ser feita principalmente com base no tipo de exploração pretendida, seja ela a produção florestal (madeira, celulose, resinas etc.), a produção animal (leite, carne, lã etc.) ou um sistema misto em que se deseja obter produtos comercializáveis ou não. Na escolha da espécie arbórea a ser implantada em um SSP, além de considerar sua adaptação às condições locais, deve-se optar por aquelas que sejam de crescimento rápido, que dentro de 1 a 2 anos a maioria das árvores já tenha atingido altura tal que posicione suas copas acima do alcance dos animais, com diâmetro suficiente para que sejam minimizados possíveis danos mecânicos (CASTRO; PACIULLO, 2006).

A escolha de espécies florestais para associação com pastagens requer conhecimentos sobre as características das espécies arbóreas mais apropriadas, de forma a viabilizar essa associação, sem trazer prejuízos aos animais ou à pastagem, quando a produção animal é o objetivo principal (MONTOYA; BAGGIO, 2000). Quando a finalidade do plantio florestal for madeira, busca-se o fuste retilíneo, condição favorecida pelo plantio em densidade maior ou na capoeira. Assim, por exemplo, é o Pterogyne nitens Tull., que produz bom tronco na mata, mas é ramificado e tortuoso em ambiente aberto (POTT e POTT, 2003).

Dentre os critérios de seleção das espécies arbóreas para o SSP, Oliveira et al. (2003) citaram o uso múltiplo, preferencialmente de leguminosas, árvores com potencial econômico (sem efeito tóxico para os animais e para o pasto) e árvores de rápido crescimento e que não apresentam copa muito densa "fechada", que não prejudique o desenvolvimento do capim embaixo da copa e que não seja invasora, ou seja, que não se alastrem pelo pasto sem controle. 
Portanto, devem-se buscar espécies adequadas às condições ecológicas do lugar; compatíveis com outros componentes do sistema; espécies adequadas à prática agroflorestal que se quer implantar, por exemplo, raízes profundas para as espécies de barreiras quebra-vento, leguminosas quando se deseja aumentar a fertilidade do solo, tolerância ao corte para forrageiras; espécies de silvicultura conhecidas, entre outros (MONTOYA; BAGGIO, 2000).

A escolha de árvores apropriadas para o estabelecimento do SSP é fundamental para o sucesso desse sistema. Melo e Zoby (2004) apontaram outras características desejáveis nas espécies para arborização de pastagens, como ser perenifólia, ser resistente a ventos, propiciar alimento ao animal, fixar nitrogênio, possuir troncos altos e copa pouco densa de modo a possibilitar a passagem de luz, permitindo assim o desenvolvimento da forrageira embaixo de sua copa.

A arborização de pastagens com espécies florestais madeireiras ou fixadoras de nitrogênio tem como objetivos diversificar a renda do produtor e contribuir para a sustentabilidade da pastagem. Espécies exóticas como Eucalyptus spp., Grevillea robusta e Pinus spp. são utilizadas com sucesso em diferentes regiões brasileiras, conciliando proteção ambiental e uso mais eficiente da terra. No entanto, várias espécies florestais nativas são indicadas para a produção de madeiras valiosas, possuem silvicultura conhecida e apresentam possibilidade de corte aos 15-20 anos, características que as tornam uma possível alternativa ao uso de espécies exóticas (CARVALHO, 2003).

Dentre as vantagens de utilizar espécies lenhosas nativas, tem-se a contribuição para a conservação da biodiversidade regional, protegendo, ou expandindo, as fontes naturais de diversidade genética da flora em questão e da fauna a ela associada, podendo também representar importantes vantagens técnicas e econômicas devido à proximidade da fonte de propágulos, facilidade de aclimatação e perpetuação das espécies (OLIVEIRA FILHO, 1994).

A madeira das espécies lenhosas nativas brasileiras é muito valorizada, mas a exploração de matas primárias está diminuindo devido à redução dos estoques. Uma alternativa para produzir essas madeiras é o plantio dessas espécies em arranjos mistos, em SSP, sendo especialmente adequados para a produção de madeira para serraria e laminação, porque os espaçamentos maiores do que os utilizados em florestas plantadas comerciais favorecem o desenvolvimento em diâmetro do tronco (RUSCHEL et al., 2003).

O plantio combinado de espécies lenhosas nativas visa reduzir riscos de pragas e doenças, obter efeitos complementares pela diversidade (oferta de abrigo, alimentos e outros recursos para a fauna e aporte de nitrogênio, por exemplo), bem como permitir maior flexibilidade na seleção de plantas ao longo do tempo para raleamento e/ou para geração de renda (RUSCHEL et al., 2003). A adaptação do componente arbóreo às condições locais é fundamental para o sucesso dos sistemas agroflorestais e as espécies que ocorrem naturalmente na região têm mais chances de se desenvolverem adequadamente. Nesse caso, as árvores podem ser preservadas em pequenos grupos, constituindo os conhecidos bosquetes, ou mantidas em faixas, condição que em muito facilita as operações de preparo do solo para a formação da pastagem (CASTRO; PACIULLO, 2006).

Ainda conforme Castro e Paciullo (2006), para obter melhoria na fertilidade do solo deve-se priorizar a utilização de espécies nativas e, dentre as espécies já estudadas pela Embrapa Gado de Leite, destaca-se a Mimosa artemisiana (Heringer \& Paula) por apresentar crescimento rápido e alta capacidade para adicionar nutrientes à pastagem de gramíneas. No entanto, outras espécies nativas também são recomendadas, como Anadenanthera macrocarpa (Benth.) Brenan, Anadenanthera colubrina (Vell.) Brenan, Dalbergia nigra ((Vell.) Allemão ex Benth.) e Piptadenia spp. 


\subsection{Espécies lenhosas nativas com potencial de uso em SSP no Estado de Mato Grosso do Sul}

Em um experimento conduzido na área experimental da Embrapa Gado de Corte, situada no Município de Campo Grande, Melotto et al. (2009) avaliaram 11 espécies florestais. As espécies que obtiveram as melhores combinações dos acréscimos em altura, diâmetro do caule e sobrevivência e que podem ser utilizadas em Sistemas Silvipastoris na região dos cerrados de Campo Grande foram chico-magro (Guazuma ulmifolia (Lam.)), carobinha (Jacaranda decurrens (Farias \& Proença)) e canafístula (Peltophorum dubium (Spreng.) Taub.).

Ainda segundo Melotto et al. (2009), para obter sucesso na implantação de um SSP na região de Cerrado de Campo Grande deve-se preferencialmente utilizar mudas de espécies pertencentes aos grupos ecológicos iniciais da sucessão, adequadas à região, respeitando, assim, suas condições ecofisiológicas e minimizando os prejuízos econômicos decorrentes de eventuais replantios.

Duleba (2009) relatou que a primeira etapa da implantação do SSP no município de Jardim e, durante seu experimento, priorizou a escolha de espécies que possuem potencial de produção de diversos benefícios diretos e indiretos, tais como:

a) produção de madeira para uso próprio na propriedade rural como a aroeira (Myracrodruon urundeuva Fr. All.), e o angico-vermelho (Anadenanthera spp.);

b) espécies que aperfeiçoem as práticas sustentáveis como cumbaru (Dypteryx alata Vogel), cujas amêndoas fornecem óleo utilizado em tratamentos medicinais, bem como bastante apreciadas pela população regional;

c) espécies que fornecem alimentação animal através da forragem em forma de folhas, ramos, frutos e sementes como a mangaba ((Hancornia speciosa) Nees \& C. Mart.) Mull. Arg., e figueira (Ficus spp.);

d) espécies que atraem a fauna nativa, principalmente aves como o manduvi ((Sterculia apelata (Jacq.) H. Karst.), e pequi (Caryocar brasiliense Cambess.);

e) espécies com silvicultura pouco conhecida, com poucos dados de crescimento em plantios experimentais como o cebolão (Phytolacca dioica L.).

Ainda conforme Duleba (2009), análises mostraram que algumas mudas se adaptaram melhor às condições edáficas e hídricas. A aroeira (M. urundeuva), manduvi (S. apétala), a caroba (Jacarandá cuspidifolia Mart.), o para-tudo ((Tabebuia caraíba) Silva Manso), e o tarumã (Vitex polygama Cham.) se adaptaram melhor às condições no campo, apresentando uma taxa de mortalidade muito baixa. Dentre as espécies que apresentaram taxa de mortalidade elevada, foram citadas o mandiocão (Didymopanax morototonii Aubl.), o pequi (C. brasiliense) e a pororoca ((Rapanea ferruginea) Ruiz \& Pav.) Mez, sendo necessário fazer o replantio dessas espécies por várias vezes.

Santos et al. (2009) descreveram algumas experiências observadas durante viagens de coleta de dados de pesquisa em diversas fazendas do Pantanal sul-mato-grossense, tais dados foram obtidos por produtores que utilizam o sistema natural tradicional e por aqueles que implementam modificações no sistema com a introdução de novas tecnologias e práticas de manejo.

Ainda conforme Santos et al. (2009), deu-se importância para algumas das diversas espécies que compõem o sistema natural, tais como o uso da bocaiúva (Acrocomia aculeata Jacq.), canjiqueira (Byrsonima orbignyana A. Juss.), acuri (Attalea phalerata Mart. ex Spreng.), para-tudo (Tabebuia aurea Manso) e aroeira (Myracrodruon urundeuva Fr. All.)(Alemão). O Pantanal ainda sofre desmatamento provocado pela introdução de gramíneas exóticas, pois a grande maioria dos fazendeiros substitui as pastagens nativas, que são pouco usadas pelo gado (áreas de "macegas"), por pastagens cultivadas. No entanto, uma prática que vem sendo muito utilizada em áreas de campo cerrado é a manutenção das espécies arbustivas e arbóreas nativas, mantendo assim o padrão natural das paisagens. 
Pott e Pott (2003) relataram que em SSP a escolha de espécies adequadas é um fator-chave. Espécies nativas podem ter maior probabilidade de êxito, porque já estão adaptadas ao meio, principalmente ao clima e ao solo. Com aquele objetivo, os autores acima realizaram um levantamento a fim de fornecer algumas informações preliminares sobre as espécies que podem ter mais sucesso nas condições do Mato Grosso do Sul. Através disso, sugeriram várias espécies lenhosas nativas (Tabela 1) com potencial de uso em sistemas agroflorestais no Mato Grosso do Sul, entre elas, devido às múltiplas utilidades, destacam-se: bocaiúva (A. aculeata), buriti (Mauritia flexuosa L. f.), chico-magro (G. ulmifolia), cumbaru (D. alata), embaúba (Cecropia pachystachya Trécul), ingá (Inga vera Willd.), jatobá ((Hymenaea courbaril var. stilbocarpa (Hayne) Y. T. Lee \& Langenh) e (Hymenaea stigonocarpa Mart. Ex Hayner var. stigonocarpa), pequi (C. brasiliense), periquiteira (Trema micrantha (L.) Blume.) e tarumã (V. cymosa).

Tabela 1. Algumas espécies nativas com potencial para SSP em Mato Grosso do Sul.

\begin{tabular}{|c|c|}
\hline Nome popular ou comum & Nome científico \\
\hline Acuri, bacuri & Attalea phalerata \\
\hline Águapomba, pitomba & Talisia esculenta \\
\hline Angico & Anadenanthera colubrina \\
\hline Angico-do-cerrado & Anadenanthera peregrina \\
\hline Aroeira & Myracrodruon urundeuva \\
\hline Bálsamo & Pterogyne nitens \\
\hline Bocaiúva, macaúba & Acrocomia aculeata \\
\hline Buriti & Mauritia flexuosa \\
\hline Camboatá & Matayba guianensis \\
\hline Capitão & Terminalia argêntea \\
\hline Capitão-do-seco & Terminalia fagifolia \\
\hline Carvoeiro & Sclerolobium paniculatum \\
\hline Capitão & Terminalia argêntea \\
\hline Caviúna-do-campo & Dalbergia miscolobium \\
\hline Chico-magro & Guazuma ulmifolia \\
\hline Cumbaru, baru & Dipteryx alata \\
\hline Cupari & Rheedia brasiliensis \\
\hline Embaúba & Cecropia pachystachya \\
\hline Figueiras & Ficus spp. \\
\hline Ingá & Inga vera ssp. affinis \\
\hline Jatobá-do-cerrado & Hymenaea stigonocarpa \\
\hline Jatobá-mirim & Hymenaea courbaril \\
\hline Mangaba & Hancornia speciosa \\
\hline Maria-mole & Erythrina dominguezii \\
\hline
\end{tabular}




$\begin{array}{cc}\text { Mulateira, angico-branco } & \text { Albizia niopioides } \\ \text { Pau-de-viola } & \text { Citharexylon myrianthum } \\ \text { Pequi } & \text { Caryocar brasiliense } \\ \text { Periquiteira } & \text { Trema micrantha } \\ \text { Piúva, ipê-roxo } & \text { Tabebuia impetiginosa } \\ \text { Piúva-cascuda, ipê-amarelo } & \text { Tabebuia ochracea } \\ \text { Pombeiro, pau-de-pombo } & \text { Tapirira guianensis } \\ \text { Sobre } & \text { Emmotum nitens } \\ \text { Tamanqueira } & \text { Aegiphila spp. } \\ \text { Tarumã } & \text { Vitex cymosa } \\ \text { Tarumarana } & \text { Buchenavia tomentosa } \\ \text { Tinge-cuia } & \text { Agonandra brasiliemsis } \\ \text { Ximbuva, timbaúva } & \text { Enterolobium contortisiliquum }\end{array}$

Fonte: Adaptado de Pott e Pott (2003).

Segundo Pott e Pott (2003), existem ainda várias outras espécies com potencial para utilização em recuperação e replantio no Mato Grosso do Sul, que, por serem ainda pouco conhecidas ou ocorrerem em área mais restrita, não foram abordadas.

\section{Conclusão}

Um SSP bem manejado é uma excelente forma para empregar árvores lenhosas nativas visando fins múltiplos, dentre os quais substituir espécies exóticas como Eucalyptus ssp.

O sucesso do SSP depende muito da escolha e da adaptação das espécies às condições locais de implantação.

No Estado de Mato Grosso do Sul, algumas espécies nativas se adaptam bem ao SSP e podem ser utilizadas, tendo apresentado maior destaque: a aroeira ( $M$. urundeuva), a bocaiúva ( $A$. aculeata), o chico-magro (G. ulmifolia) e o cumbaru (D. alata), pois são recomendadas por mais de um autor.

\section{Native woody species with potential use in silvopastoral system in Mato Grosso do Sul}

\section{Abstract}

Silvopastoral systems (SSP) are natural associations, planned or converted from pasture with tree species. When handled properly, this system keeps the soil and water resources and promote 
carbon sequestration and biodiversity enhancement. In order to obtain quantitative information on the subject, we carried out a study on the benefits and importance of the choice of several species in the SSP, reporting some native woody species with potential for use in silvopastoral systems in the state of Mato Grosso do Sul. The work was conducted through literature review, with objective and cohesive context. With this study we can say that the success of SSP depends on the choice and adaptation of tree species to local local conditions of deployment. However, in the State of Mato Grosso do Sul, some native species adapt well to the SSP and can be used, such as mastic (Myracrodruon urundeuva), bocaiúva (Acrocomia aculeata), chico-magro (G. ulmifolia) and cumbaru (Dypteryx alata).

Key-words: Trees. Association. Pasture. Silviculture.

\section{Referências bibliográficas}

$A B E L, N$. et al. Design principles for farm forestry: a guide to assist farmers to decide where to place trees and farm plantations on farms. Thebarton (Austrália): Finsbury Press Pty, 1997. Disponível em: <http://live.greeningaustralia.org.au/nativevegetation/pages/pdf/Authors\%20A/2_ Abel_Baxter_et_al.pdf >. Acesso em: 22 mai. 2013.

ANDRADE, C. M. S. et al. Árvores de baginha (Stryphnodendron guianense (Aubl.) Benth.) em ecossistemas de pastagens cultivadas na Amazônia Ocidental. Revista Brasileira de Zootecnia, Piracicaba, v. 31, n. 2, p.574-582, mar./abr. 2002.

BAGGIO, A. J.; CARPANEZZI, O. B. Alguns sistemas de arborização de pastagens. Boletim de Pesquisa Florestal, Colombo, n.17, p.47-60, dez. 1988.

CARVALHO, M. M. et al. Estabelecimento de sistemas silvipastoris: ênfase em áreas montanhosas e solos de baixa fertilidade. Juiz de Fora: Embrapa Gado de Leite, 2002. 12 p. (Embrapa Gado de Leite. Circular Técnica; 68).

CARVALHO, M. M. et al. Crescimento inicial de cinco gramíneas tropicais em um sub-bosque de angico-vermelho (Anadenanthera macrocarpa Benth.). Pasturas Tropicales, v.17, n.1, p. 24-30, 1995.

CARVALHO, P. E. R. Espécies arbóreas brasileiras. Colombo: Embrapa Florestas, 2003. v. 1, 1039p.

CASTRO, C. R. T.; PACIULLO, D. S. C. Boas práticas para a implantação de sistemas silvipastoris. Juiz de Fora: Embrapa, 2006. (Comunicado técnico 50) Disponível em: <http://ainfo.cnptia. embrapa.br/digital/bitstream/item/44226/1/COT-50.pdf>. Acesso em: 22 mai. 2013.

DANIEL, O. et al. Sistemas agroflorestais (silvipastoris e agrissilvipastoris) na região centro-oeste do Brasil: potencialidades, estado atual da pesquisa e da adoção de tecnologia. In: SIMPÓSIO INTERNACIONAL SISTEMAS AGROFLORESTAIS PECUÁRIOS NA AMÉRICA DO SUL, 2000. Juiz de Fora. Anais... Juiz de Fora: Embrapa Gado de Leite, FAO, 2000. CD-ROM.

DANTAS, M. Aspectos ambientais dos sistemas agroflorestais. In: CONGRESSO BRASILEIRO SOBRE SISTEMAS AGROFLORESTAIS, 1994, Porto Velho. Anais... Colombo: EMBRAPA/ CNPQFlorestas, 1994. v.1. p. 433-453. 
DIAS FILHO, M. B. Sistemas silvipastoris na recuperação de pastagens degradadas. In: SIMPÓSIOS DA REUNIÃO DA SOCIEDADE BRASILEIRA DE ZOOTECNIA, 43. João Pessoa. Anais... João Pessoa: SBZ: UFPB, 2006. (Suplemento Especial da Revista Brasileira de Zootecnia, v. 35, 2006). p. 535-553.

DUBOIS, J. C. L. Alternativas agroflorestais para recuperação de solos degradados na região norte do Brasil. In. SIMPÓSIO NACIONAL SOBRE RECUPERAÇẪO DE ÁREAS DEGRADADAS. 1992. Curitiba. Anais... Curitiba: FUPE/UFPR, p. 107-125.

DULEBA, S. Primeira etapa de implantação do sistema silvipastoril: fazenda Cabiceira do Prata. Jardim: [s.n.], 2009. Disponível em: <http://www.pantanalecoturismo.tur.br/fotos/arquivos/596. pdf >. Acesso em: 22 mai. 2013.

FRANKE, I. L.; FURTADO, S. C. Sistemas silvipastoris: fundamentos e aplicabilidade. Rio Branco: Embrapa Acre, 2001. 51 p. (Embrapa Acre. Documentos; 74).

FRANKIE, I. L. et al. Comportamento de espécies arbóreas de uso múltiplo para sistemas agroflorestais no estado do Acre. In: CONGRESSO BRASILEIRO DE SISTEMAS AGROFLORESTAIS - SISTEMAS AGROFLORESTAIS: MANEJANDO A BIODIVERSIDADE E COMPONDO A PAISAGEM RURAL. Manaus, 2000. Anais... Manaus: Centro de Pesquisa Agropecuária da Amazônia Ocidental - EMBRAPA. 2000. p. 97-100.

INSTITUTO BRASILEIRO DE GEOGRAFIA E ESTATÍSTICA. Censo agropecuário 2006. Disponível em: http://www.ibge.gov.br/estadosat/temas. php?sigla=ms\&tema=censoagro. Acesso em: 5 jan. 2013.

KAGEYAMA, P. Y.; CASTRO, C. F. A. Sucessão secundária, estrutura genética e plantações de espécies arbóreas nativas. IPEF, Piracicaba, n.41/42, p.83-93, 1989.

LEME, T. M. S. P. et al. Comportamento de vacas mestiças Holandês x Zebu, em pastagem de Brachiaria decumbens em sistema silvipastoril. Ciência e Agrotecnologia, v. 29, n. 3, p. 668675, mai./jun. 2005.

MACEDO, R. L. G.; CAMARGO, I. P. Sistemas agroflorestais no contexto do desenvolvimento sustentável. In: CONGRESSO BRASILEIRO SOBRE SISTEMAS AGROFLORESTAIS. 1994. Porto Velho. Anais. Colombo: EMBRAPA/ CNPF, 1994. v.2 p.43-50.

MARLATS, R. M. et al. Sistemas silvopastoriles: estimación de benefícios directos comparados com monoculturas em La Pampa Ondulada, Argentina. Agroforestia em lãs Americas, Turrialba, v. 2, n. 8, p. 20-25. 1995.

MELADO, J. Pastagens Ecológicas: o habitat natural do bovino Orgânico. In: PRIMEIRA CONFERÊNCIA GLOBAL VIRTUAL SOBRE PRODUÇÃO ORGÂNICA DE BOVINOS DE CORTE. Embrapa Pantanal Corumbá e Universidade do Contestado, Concórdia. 2002. $21 \mathrm{p}$.

MELO, J. T.; ZOBY, J. L. F. Espécies para arborização de pastagem. Planaltina: Embrapa, 2004. (Comunicado técnico 113) Disponível em: < http://www.google.com.br/url?sa=t\&rct=j\&q=\&esrc= s\&source $=$ web\&cd = 1\&cad =rja\&ved =0CDAQFjAA\&url =http\%3A\%2F\%2Fwww.cpac.embrapa.br\% 2Fdownload\%2F237\%2Ft\&ei=Zd6cUbDwM-Hm0gHb9oGgAg\&usg=AFQjCNEW6v_1djX_uODtvW Tq3kMYoHFAUw\&bvm=bv.46751780,d.dmQ> . Disponível em: 22 mai. 2013. 
MELOTTO, A. et al. Sobrevivência e crescimento inicial em campo de espécies florestais nativas do Brasil central indicadas para sistemas silvipastoris. Revista Árvore, Viçosa, v. 33, n. 3, p. 425432, mai./jun. 2009.

MONTOYA VILCAHUAMAN, L. J.; BAGGIO, A. J. Guia prático sobre arborização de pastagens. Colombo-PR: Embrapa Florestas, 2000. 16p. (Embrapa Florestas. Documentos, 49).

MURGUEITIO, E. et al. Produção de leite com sistemas silvipastoris intensivos. In: CONGRESSO LATINOAMERICANO DE SISTEMAS AGROFLORESTAIS PARA A PRODUÇÃO PECUÁRIA SUSTENTÁVEL - SAPPS. 7., Anais... 2012. Belém do Pará, UFPA.

NEPOMUCENO, A. N.; SILVA, I. C. Caracterização de sistemas silvipatoris da região noroeste do Estado do Paraná. Revista Floresta, Curitiba, v. 39, n. 2, p. 279-287, abr./jun. 2009.

NICODEMO, M. L. F. Sistemas silvipastoris: árvores e pastagens, uma combinação possível. In: ZOOTEC - PRODUÇÃO ANIMAL E RESPONSABILIDADE, 2005, Campo Grande. Anais do Zootec, Campo Grande, 2005.

OLIVEIRA-FILHO, A. T. Estudos ecológicos da vegetação como subsídios para programas de revegetação com espécies nativas: uma proposta metodológica. Revista Cerne, Lavras, v.1, n.1, p.64-72, jan./dez. 1994.

OLIVEIRA, T. K. et al. Sugestões para implantação de sistemas silvipastoris. Rio Branco: Embrapa Acre, 2003. (Embrapa Acre. Documentos 84).

PORFIRIO-DA-SILVA, V. Arborização de pastagens: procedimentos para introdução de árvores em pastagens. Colombo: Embrapa Florestas, 2006. (Comunicado técnico 155).

POTT, A.; POTT, V. J. Plantas Nativas Potenciais para Sistemas Agroflorestais em Mato Grosso do Sul. In: SEMINÁRIO SISTEMAS AGROFLORESTAIS E DESENVOLVIMENTO SUSTENTÁVEL. Campo Grande. 2003. Anais... Campo Grande: Embrapa, 2003.

RIBASKI, J. et al. Avaliação de um sistema silvipastoril com Eucalipto (Corymbia citriodora) e braquiária (Brachiaria brizantha) no noroeste do Paraná. In: CONGRESSO FLORESTAL BRASILEIRO, 8. São Paulo. Anais... São Paulo: Sociedade Brasileira de Silvicultura. 2003.

RUSCHEL, A. R. et al. Evolução do uso e valorização das espécies madeiráveis da Floresta Estacional Decidual do Alto-Uruguai. Ciência Florestal, Santa Maria, v. 13, n. 1, p. 153-166. 2003.

SANTOS, S. A. et al. Sistemas silvipastoris naturais e alterados no pantanal. Embrapa Pantanal. Revista Brasileira de Agroecologia. v. 4 n. 2 p. 1556-1559, nov. 2009. (Resumos do VI CBA e II CLAA)

SEGHESE, M. A. Projeto vida no campo: a vida em harmonia com a natureza: sistemas agroflorestais, sistemas de produção agrossilvipastoril diversificado, integrado, sustentável e orgânico. Sete barras: [s.n.], 2006. Disponível em: <http://www.cesumar.br/graduacao/arquivos/ projeto_vida_no_campo.pdf $>$. Acesso em: 22 mai. 2013. 
SILVA, V. P. Sistemas silvipastoris em Mato Grosso do Sul - Para que adotálos? In: Seminário Sistemas Agroflorestais e Desenvolvimento Sustentável, 2003, Campo Grande. Anais... Campo Grande: Embrapa, 2003. CD-ROM.

\section{Histórico editorial}

Recebido: 26/02/2013

Avaliação e copidesque: 27/02/2013 a 13/06/2013 